coveries in nature causing continual occasion for amended translations of various texts; whereas, should the view which has been advocated in this chapter be found correct, instead of learing that the future progress of sci. ence may raise additional difficultits in the way of revealed religion, we are at once relieved fiom all doubt on that subject,-Babbage's Brilgewater Trealise, p. 63.

Ed. Now Philos. Jour.

\title{
The November-Asterüis.
}

Nolice of a recent Communicalion relating to them, by Dr. OLBens.

Those who take an interest in pilysical sciences bave, within these few years, hat thair allention directed to the periolical return of shouting-stars; and recent observations go far to subvert the opinions formerly held with respect to them-mancty, that they originated within the limits of our atmosphere. On the corrtiary, it is now foobed upon as an established fact, that they are beavenly bothes of inconsilerable dimensiuns, but which, in common with all others of a similar nature, have, of course, a regular motion. 'They are, in short, supposed to represent, in the solar system, the arjimacules of the animal kingilon.

Olbers, in the Jahrbuch fur 1837 , brings forward, with irresistible force and clearness, numerous profof in favour of this supposition; and the following general stetrh will, it is hoped, give a faithtul abstract of the arguments to which he thereis has recuese, in favour of the new theory.

On the 12th of November, 1795, before sun-rike, llumbollt and Bonp. land, on the coast of Mexico, observed, during four hours, a succession of many thousand shootiog-stirs and small firc-balls. The part of the heavens whence they emanatef lay due east, and the y extended over a space of $30^{\circ}$ to the right and left of that point. They rose above the horiz'sn in an eastnorth-east direction, and fell towards the south, describing unequal arcs in their course. Some atlained an altitude of $40^{\circ}$, and there were nome that did not rise to between $2.5^{\circ}$ and $30^{\circ}$. Several appeared to burst; the largest, however, disappeared, without throwing unt any coruscations. Some had a large nucleus equal to Jupiter in brightness, and all, or nearly so, had tails.

This remarkable phenomenon was also simultaneously observed from various distant points of the earth. A similar display was again witnessed on the night of the 13 th of November, 1831, on the night of the 12 th of Novemuer, 1832, on the same night in 1833, and on the night of the $13 \mathrm{ch}$ of November, 1834.

This periodical return induced many persons, where the cloudy state of the weather dial not altorether put a stop to their observations, to keep a good look out on the nigits between the 11 th and 14 th of November, 1836; nor was the trouble they thus took thrown away, for it appears that a vast number of shorting-star's were actually at that time observed from the most distaut points of the globe.

The periodical recurn of these bodies would thus seem to be established, but this is not suflicient for us 10 form any just notions as to their nature. The first step to be taken to that end is to discover what their elevation above the earth's surtace may be.

In order to arrive at this, two observers in concert determine the angle under which they see a shooting-star, indicating likewise the time of its appearance, and noting the star near which it came into sight. Now, if two such observers remark at the same instant, and in the same direction and 
position, any shooting-star, it may fairly enough be assumed that they are looking at one and the same object. A triangle is thus obtained; the basethat is to say the distance between the observers, and two angles of which, are approximately known, so that the calculation of the distance presents no difficulties whatever.

Simple as these observations are, it is evident that they cannot pretend to any thing like exactness; as they are, however, very numerous, their errors are thereby efiminated, and approximate results, at least, are arrived at; attd the distance being thus ascertained, their real velocity may be deduced from the apparent.

Olbers conveys his upiniong respecting these bodies in the following terms. The remarkable aud very unequal distribution of those small bodies revolving round the sun, which form the fire-balls and shooting-stars of our planetary system, as well as the general resemblance, and nearly similar nature, of all the meteoric stones which fall from time to time, (taking into consideration both their external characters, and also their chemical composition,) seem to indicate not only that they have one common origin, but also that it was one common cause which has thus hurled them into space.

One cannot help reverting, involuntarily, to the hypothesis which holds the four new planets, Vesta, Juru, Pallas, and Ceres, to be but fragments of a larger planet, fornerly revolving round the sun between $M$ ars and Jupiter, but which hias been sluattered to pieces by some violent catastrophe. On such a planet as this exploding, and being scattered about in all directions there would also be, independent of the larger fragments, innu merable nuch smaller, inderl minute pieces, hurled into space, and these would now circulate about the sun in eilipses of various degrees of eccentricity.

It inust be borne in mind that Olbers treats this, however, as a mere hypothesis and distinctly says he by no means allopts the language of Professor. Wildt, who, as inay be seen by relerring to the 9 th Volume, p. 408 , of Voigt's Magazin fur den neusten Stand der Naturkunde, unreservedly asserts, the stones which have fallen on the earth to be "the ruins of some globe which has been destoyed, and which revolve round the sun till, sooner or later, they fall in with a planet.

"They without doubt, he continues, belong to the group of Ceres, Pallas, \&c., and thus we see how it is that their appearance and composition bear such general resemblance to each other."

What we really know of shooting-stars, of those, at least, which a re allied to tire-balls, if not actually identical with then, may be summed up in the following words:-

1st. They move at considerable elevations above the earth, their distances from it ranging from between 140 to 190 miles.

Qndly. Their velocity is equal to that of several of the planets; and their relative velocity, conpared with the earth, may vary from 37 to 42 niles in a secord, *

Srdly. Hence it is from without the regions of space that they en ter our atmosphere, and it is not within the limits of the latter that they originally. take their rise.

4 thly. They are not ejected into the earth from the moon.

Much that is connected with these interesting meteors, it is, however, quite out of our power to explain. For instance, bow is it they become jgnited? How is it that, in the extremely rare medium in which they move,

* Liltruw gives the mean velocity of Mercury only at 30 miles per second, that of the earth at 19 miles, and the mean of the four new planets at 12.

Vol. XX.-No. 5.-November, 1837. 
they continue glowing, or, indecd, burning with such brilliancy? Ilow can the comparatively small nass of the meteoric stones which falls to the eartl expand in those elevated regions to bodies several hundred feet in dianeter?

Must we not suppose, with the acute Von Hoff, of Gotha, that the materials of which shooting stars originally consist are submitted to a peculiar chemical process upon entering into our atmosphere, the result of which is the formation of the substance we see fall as meteoric stones, - a process which surely cannot consist merely of fusion?

All these questions, and many otbers of a similar nature, will possibly remain for ever unanswered, or be, at least, but unsatisfactorily solverl; for it scarcely appears probable that time can give $n$ s a reeper insiulin into the circumstances contected with this subject. How can we, imicer, even hope to arrive at a satisfactory knowled of processes carried on at altitudes where the air is far rarer than in the most perfect vacuan we can protuce, and where, moreover, the atmonghere possibly consists of gyases of which we know nothing, and all carried on at a temperalure of absolute cold, What powers, aftinty, electricity, and magnetism are there invested with, will always remain a mystery to us.

Munich, 10h kihy, $189,7$.

s.

Mar. Iun. sici.

\section{St. Ilmo's Fire sem in Orkney.}

During last February, 1837. (Sunday 19,) in a tremendous gale, my large boat sunk, and it was late on luestay night before we coult get her up and drawn to the shore, alter which we bad to wait ill three o'cluck next morning till the lide ebbed from her; she was doring this time attachest to the shore by an iron chain, abont 30 fathoms lone, which did not touch the water, when, to my nstonichment, I behelt a sheet of bloot-red name, extending along the shore for about 30 fathoms broal and 100 falhoms long, commencing at the chain and stretching along the shore and sea the threction of the shore which was $\mathrm{K}$. S. k., the wind being $N$. N. W. at the time. The tlame remained about ten seconds, and occurred four times in about two minutes. Whilst I was wondering not at litle, the bonturib, who, to the number of twenty-five or thirty, were shellering themsetses tron the weather, came running down apparently alamed, and asked me i had ever seen anything like this before. I was about to reply, when I observed their eyes directed upwards, and found they were attracted by a most splendid appearance at the boat. The whole mast was illuminated, and from the iron spike at the summit, a lame of one foot long was pointed to the N. N. W., from which a thunder-cloud was rapidly coming. 'The cloud approached, which was accompanied by thunder and hail; the lame in. creased and followed the course of the cloud till it was immediately above, when it arrived at the length of nearly three feet, after which it rapidy diminished, still pointing to the cloud, as it was borne rapidly on $10 \mathrm{~S}, \mathrm{S.}$. The whole lasted about four minutes, and had a most eplendidappenance. 1 regretted afterwards that I was so occupied with the thame at the mast head that I did not observe whether the red lame on the ground continued during the lime the cloud was passing.-Extrat of a Letter fiom Hillum Traill, Esq., Kirkwall, to Prafessor Traill, daled Why 16, 1837. 